\title{
Single catheter approach for occlusion of a patent arterial duct with a Rashkind double umbrella
}

\author{
Simon E Abrams, Kevin P Walsh, Elizabeth A McDonald, Anne E Boothroyd
}

\begin{abstract}
Objectives-To determine the benefits of using a single venous catheter and a single angiogram during catheter occlusion of a patent arterial duct with the Rashkind double umbrella compared with those of venous and arterial catheters and multiple angiograms.

Design-Retrospective review of case notes.

Patients-103 consecutive patients. The long sheath could not be advanced adequately in two patients. 101 patients had 104 implantations. Median (range) age was 35 (7-549) months and median (range) weight 13 (7-62) kg. Fifty four implantations were performed using the venous and arterial method and 50 using the venous only method.

Results-Median procedure times (70 $v$ $90 \mathrm{~min}$ ), number of angiograms (one $v$ four), and angiographic dye volume used (2 $v 7 \mathrm{ml} / \mathrm{kg}$ ) were significantly reduced using the venous only method compared with those of the venous and arterial method. There was no significant difference in fluoroscopy time (venous only $9 v$ venous and arterial $10 \mathrm{~min}$ ).

Conclusions-Considerable improvements can be made in the technique of catheter closure of patent arterial ducts using the Rashkind double umbrella without compromising outcome using venous cannulation alone and a single angiogram, rather than venous and arter-
\end{abstract}

Table 1 Demographic data for all patients and the separate groups

\begin{tabular}{|c|c|c|c|c|c|c|}
\hline & $\begin{array}{l}\text { No of } \\
\text { pts }\end{array}$ & $\begin{array}{l}\text { No of } \\
\text { boys }\end{array}$ & $\begin{array}{l}\text { No of } \\
\text { girls }\end{array}$ & $\begin{array}{l}\text { Weight } \\
\text { (kg) }\end{array}$ & $\begin{array}{l}\text { Age at } \\
\text { presentation } \\
\text { (months) }\end{array}$ & $\begin{array}{l}\text { Age at } \\
\text { procedure } \\
\text { (months) }\end{array}$ \\
\hline $\begin{array}{l}\text { All patients } \\
\text { Venous only } \\
\text { Failed }\end{array}$ & $\begin{array}{r}103 \\
51 \\
7\end{array}$ & $\begin{array}{r}28 \\
14 \\
3\end{array}$ & $\begin{array}{r}75 \\
37 \\
4\end{array}$ & $\begin{array}{l}13(7-62) \\
14(7-62) \\
12(9-50)\end{array}$ & $\begin{array}{l}27(0-199) \\
34(0-199) \\
43(18-197)\end{array}$ & $\begin{array}{l}35(7-549) \\
41(9-549) \\
37(0-192)\end{array}$ \\
\hline $\begin{array}{l}\text { venous only } \\
\text { Venous } \\
\text { and arterial }\end{array}$ & 52 & 14 & 38 & $13(7-48)$ & $22(0-163)$ & $30(7-164)$ \\
\hline
\end{tabular}

Values are median (range). There were no significant demographic differences between groups except for age at procedure.
(Br Heart $\mathcal{F} 1995 ; 74: 300-304)$

Keywords: venous catheter closure; patent arterial duct; Rashkind double umbrella occlusion \section{ial cannulation and multiple angiograms. The benefits are reduced radiation expo- sure, reduced risk to arteries from can- nulation, shorter procedures, and lower equipment costs. \\ Liverpool Children's \\ S E Abram \\ A E Boothroyd}

Dr K P Walsh, Roya

Hospital, Alder Hey, Eato

Accepted for publication

1 March 1995
Percutaneous catheter closure of the patent arterial duct has replaced surgery for many children weighing more than $7 \mathrm{~kg}$. The widely used technique for implantation of the Rashkind double umbrella device (USCI Bard, Galway, Ireland) in patent arterial ducts in the United Kingdom and Europe requires venous and arterial catheterisation and multiple angiograms. ${ }^{1} \mathrm{~A}$ single catheter technique is used in North America.

We have performed catheter occlusion of the patent arterial duct since 1989. Since August 1992 we have changed to a single venous catheter method in conjunction with a single angiogram, where possible. We have reviewed and compared the results of 51 patients treated with the "venous only" technique with those of our initial 52 patients in whom the conventional "venous and arterial" technique was used.

The objectives of the change over were to improve safety and efficiency by shortening procedure times, reducing radiation doses for patients and operators, and reducing costs.

\section{Patients and methods}

PATIENTS

Criteria for occlusion comprised: a patent arterial duct with a minimum diameter measuring less than $8 \mathrm{~mm}$ as measured on two dimensional echocardiography, left to right shunting, patient weight more than $7 \mathrm{~kg}$, and no intercurrent illness. Patients intended for occlusion of a patent arterial duct with a Rashkind double umbrella device were included.

Between November 1989 and 1993, 103 patients were considered for occlusion of a patent arterial duct using a Rashkind double umbrella device. The initial attempt at duct occlusion failed in two patients: the 11 French gauge sheath could not be passed through the iliac vein in one and the sheath would not traverse the arterial duct in the second, in whom surgical ligation had failed. Three patients have had a second device deployed. Therefore 101 patients had 104 catheterisations with device deployment to occlude a patent arterial duct using a Rashkind double umbrella device. Table 1 gives demographic details. An isolated patent arterial duct was present in 94 patients $(93 \%)$. An associated cardiac anomaly was present in seven patients (bicuspid aortic valve (one), aortic stenosis (one), small ventricular septal defect (two), ventricular septal defect and pulmonary stenosis (one), mitral valve prolapse with regurgitation (one), 
moderate atrial septal defect (one). One patient had Down's syndrome and one had bronchopulmonary dysplasia with moderate pulmonary hypertension (pulmonary artery pressure $52 / 26 \mathrm{~mm} \mathrm{Hg}$ ).

\section{MATERIALS AND METHODS}

Shared methods

Rashkind double umbrella devices with a diameter of $12 \mathrm{~mm}$ were used to occlude patent arterial ducts of less than $4 \mathrm{~mm}$ in diameter $(\mathrm{n}=92)$ and devices of $17 \mathrm{~mm}$ in diameter for ducts between 4 and $8 \mathrm{~mm}$ in diameter $(n=12)$. Angiograms were performed using biplane cineangiography in anteroposterior and lateral views. Non-ionic contrast medium (Omnipaque 350; Nycomed Ltd, Birmingham, UK) was injected using a pressure injector with doses of $1-2 \mathrm{ml} / \mathrm{kg}$ at rates of $6-30 \mathrm{ml} / \mathrm{s}$. A long sheath, via a venous approach, was used for introducing, deploying, and releasing the device as previously described by Rashkind et al. ${ }^{2}$ The initial diagnostic angiogram was recorded onto high quality video tape and the lateral projection reviewed to measure the minimum arterial duct diameter for correct device selection and identify the position of the arterial duct relative to the trachea. These landmarks were used to facilitate accurate positioning of the device. In particular the position of the narrowest part of the arterial duct relative to the anterior and posterior borders of the trachea, any additional intraluminal stenoses and the duct morphology ${ }^{3}$ were noted. A chest radiograph and a two dimensional echocardiograph with colour flow imaging and Doppler were performed the day after implantation to demonstrate the device in position and assess any residual shunting. Patients were reviewed in the outpatients department at intervals of about 1, 6, and 12 months with serial echocardiography and colour flow Doppler to assess residual shunting.

\section{Venous and arterial method}

Diagnostic studies before and after placement were performed using 6 or 7 French gauge multipurpose "A2" catheters (Cordis, Belgium) through a 6 or 7 French gauge haemostatic valve (USCI Bard) for venous access, and a 4 or 5 French gauge pigtail catheter (Mallinckrodt, United States), usually inserted percutaneously over a guidewire, for arterial access. Angiograms, via the arterial pigtail catheter, were routinely performed at the following stages of the procedure: $(a)$ with the venous catheter in the main pulmonary artery; (b) with the venous catheter through the arterial duct; (c) after placement of the device but before release; and (d) after deployment of the device.

\section{Venous only method}

A 6 French gauge haemostatic sheath, introduced percutaneously into the femoral vein, was used in children less than $10 \mathrm{~kg}$ in weight and a 7 French gauge sheath in children over $10 \mathrm{~kg}$. A 6 or 7 French gauge Gensini catheter (Balt, France) was passed through the right heart and across the patent arterial duct with the most proximal holes in the aortic end of the duct. Only one diagnostic angiogram was performed. No further angiograms were performed before or after deployment of the device. The landmarks on the lateral projection angiogram were reviewed immediately before release. The same release technique was used as that for the venous and arterial group. Deployment and release were the same as those of the venous and arterial method. Release was recorded on cine film. Fluoroscopy was used to check the position after release.

\section{Radiation measurement}

The actual radiation exposure received by the patient was measured directly in three cases from the venous only group. Measurements of radiation exposure in posteroanterior and lateral planes were made using calibrated exposure factors. Direct exposure measurements were therefore available for each angiogram and fluoroscopy during those procedures. The number of frames for each angiogram for these three patients was counted using the frame counter on an angiogram projection system and measurement of the radiation dose per cine frame and the radiation dose per minute of fluoroscopy were calculated. The number of frames from 30 angiograms from the whole series was then counted and a mean and standard deviation calculated. Subsequently, the average radiation exposure for each group was calculated by multiplying the mean number of frames per angiogram, the number of angiograms, and the radiation dose per cine frame. The mean fluoroscopy dose for each group was then added to give a total radiation exposure. Results are expressed in milligrays. The bioeffects are expressed as a dose equivalent in millisieverts. These are numerically equivalent for $x$ rays (photons). ${ }^{4}$ Radiation exposure was noted to be independent of patient weight ( $\mathrm{E}$ McDonald, unpublished data).

\section{STATISTICAL METHODS}

The venous only method was defined as having failed if an arterial catheter was required in the procedure or the device embolised. End points for comparative analysis were: (a) procedure time (defined as time from anaesthetic induction to reversal); (b) fluoroscopy time; (c) number of angiograms performed; (d) volume of dye per kilogram used; and (e) complete occlusion at follow up. Values are median (range). Unpaired $t$ tests for parametric data were used to compare groups. A probability value of less than 0.05 was considered significant. A $\chi^{2}$ test with Yates' correction was used to compare numbers within groups.

\section{Results}

ALL PATIENTS

Initial device placement was successful in 104 procedures. In one patient placement of a 12 $\mathrm{mm}$ device was successful and fluoroscopy $20 \mathrm{~min}$ after release showed the device in position. On the following day, however, 
Table 2 Procedure times, number of angiograms, fluoroscopy times, and dye volumes for the different groups

\begin{tabular}{lllcl}
\hline & $\begin{array}{l}\text { Procedure time } \\
\text { (min) }\end{array}$ & $\begin{array}{l}\text { No of } \\
\text { angiograms }\end{array}$ & $\begin{array}{l}\text { Fluoroscopy } \\
\text { time (min) }\end{array}$ & $\begin{array}{l}\text { Dye volume } \\
(\mathrm{ml} / \mathrm{kg})\end{array}$ \\
\hline $\begin{array}{l}\text { Venous only } \\
\text { Venous and }\end{array}$ & $70(25-135)^{\star}$ & $1(1-6)^{\star}$ & $9(4-55)$ & $2(0 \cdot 4-14)^{\star}$ \\
arterial & $90(30-230)$ & $4(2-9)$ & $10(4-61)$ & $7(3-19)$ \\
Failed venous & $100(45-120)$ & $3(1-6)^{\star}$ & $22(9-55)^{\star} \dagger$ & $4(1 \cdot 4-14)$ \\
\hline
\end{tabular}

Statistical comparisons were made with the arterial and venous group versus the venous only group and the failed venous only group versus the venous only group (*probability of less than 0.05 ) and arterial and venous group versus the failed venous group (tprobability of less than 0.05 ) (see text) chest radiograph showed that the device had embolised to the right pulmonary artery. The patient underwent catheter retrieval of the first device and successful implantation of a $17 \mathrm{~mm}$ device the following day.

The mean (SD) follow up to either discharge with no shunt or last follow up with residual shunt was 7 (10) months. Complete occlusion of the patent arterial duct occurred after placement of a first device in 74 patients 6 (9) months after implantation and a residual leak was present in 26 patients 10 (9) months after implantation. Two of these latter patients have continuous murmurs and are awaiting implantation of a second device. Two of the three patients with a second device had complete occlusion within two months. The third patient, in whom the first device embolised (see earlier), is awaiting a third procedure. All other residual shunts are trivial.

COMPARISON BETWEEN THE VENOUS ONLY AND VENOUS AND ARTERIAL GROUPS

More patients $(P<0.05)$ received a $17 \mathrm{~mm}$ device in the arterial and venous group (11 of 53) compared with that of the venous only group (two of 51).

Table 2 gives the mean (SD) for all end points aside from complete occlusion for the different groups. The venous only group had significantly shorter procedure times $(\mathrm{P}<$ $0.04)$, fewer angiograms $(P<0.0001)$, and smaller dye volumes per kilogram ( $P<$ 0.0001 ) than the venous and arterial group but similar fluoroscopy times. The failed venous only group had similar procedure times and dye volumes per kilogram, fewer angiograms $(P<0.01)$, but significantly greater screening times $(P<0.03)$, than the venous and arterial group.

There was no significant difference in the number of patients in whom complete occlusion was achieved: $39(76 \%)$ in the venous only group and $35(67 \%)$ in the venous and arterial group despite a significantly shorter
$(P<0.002)$ period before occlusion occurred in the venous only group (median (range) 0 (0-14) months) compared with that in the venous and arterial group (6 (0-66) months).

FAILURE OF THE VENOUS ONLY METHOD

Of the 51 episodes using a venous only $I$ approach, six failed and required insertion of an arterial catheter and one device embolised, $\vec{c}$ requiring catheter retrieval and reocclusion $\vec{\Rightarrow}$ with a second device. Failures were due to $\stackrel{\rho}{+}$ three causes: inability to cross a small arterial $\bar{c}$ duct from the venous side (three cases); $\frac{\bar{F}}{\overline{\frac{D}{0}}}$ inability to accurately size the duct on angio- $\frac{\vec{\sigma}}{\bar{\phi}}$ graphy (two cases); concern about the posi- $₫$ tion of the released device at the end of the $ळ$ procedure (one case). In cases in which it was $\overrightarrow{0}$ not possible to cross the arterial duct from the venous side an arteriovenous guide wire loop $\vec{\omega}$ was set up. In two of these balloon angioplasty of the arterial duct with a $4 \mathrm{~mm}$ Merck balloon (Balt, France) was required before pas- + sage of the venous long sheath. Age at $\dot{\omega}$ presentation and weight at the time of the $\varnothing$ procedure of this group was not significantly different from that of all patients but age at procedure was significantly $(P<0.04)$ older $\&$ (median (range) $37(0-192)$ months $v 27 \frac{\Phi}{0}$ (0-199) months) (table 1).

\section{RADIATION EXPOSURE}

Table 3 gives the radiation doses for the three $\vec{\emptyset}$ monitored patients. The calculated radiation 5 dose per cineangiogram frame was $0.13 \mathrm{mSv}$ and per minute of fluoroscopy was $16.5 \mathrm{mSv}$. The mean (SD) number of frames per angiogram was 265 (34). Table 4 gives the results of the calculations of mean radiation $\propto$ exposure for all patients.

\section{ARTERIOVENOUS CIRCUITS}

An arteriovenous guide wire loop was required in five patients (three in the venous only group). In all cases it was not possible to cross the arterial duct from the venous side $\frac{\sigma}{\sigma}$ and therefore it was crossed from the aortic 3 . side and a guidewire was snared in the pul- $\delta$ monary artery or inferior vena cava and $₹$ brought out on the venous side.

COMPLICATIONS

One patient in the venous only group haemorrhaged from the femoral vein and required a blood transfusion after the procedure. Two $\tilde{O}$ patients from the venous and arterial group $\tilde{\omega}$ who required arteriovenous guidewire loops lost their foot pulses after the procedure. They 0 were treated with streptokinase with return of $\Phi$ the pulses within $24 \mathrm{~h}$ in each case, however,

Table 3 Radiation doses ( $m S v$ ) in each plane during cineangiography and fluoroscopy

\begin{tabular}{|c|c|c|c|c|c|c|c|c|}
\hline \multirow[b]{2}{*}{$\begin{array}{l}\text { Patient } \\
\text { no }\end{array}$} & \multirow[b]{2}{*}{$\begin{array}{l}\text { Weight } \\
(\mathrm{kg})\end{array}$} & \multicolumn{2}{|l|}{ Angiography dose } & \multicolumn{2}{|l|}{ Fluoroscopy dose } & \multirow{2}{*}{$\begin{array}{l}\text { No of } \\
\text { cine } \\
\text { angiograms }\end{array}$} & \multirow[b]{2}{*}{$\begin{array}{l}\text { No of } \\
\text { cine } \\
\text { frames }\end{array}$} & \multirow[b]{2}{*}{$\begin{array}{l}\text { Fluoroscopy } \\
\text { time } \\
\text { (min) }\end{array}$} \\
\hline & & $\begin{array}{l}\text { Postero anterior } \\
\text { plane }\end{array}$ & $\begin{array}{l}\text { Lateral } \\
\text { plane }\end{array}$ & $\begin{array}{l}\text { Postero anterior } \\
\text { plane }\end{array}$ & $\begin{array}{l}\text { Lateral } \\
\text { plane }\end{array}$ & & & \\
\hline $\begin{array}{l}1 \\
2 \\
3\end{array}$ & $\begin{array}{r}9 \cdot 5 \\
9 \cdot 2 \\
62\end{array}$ & $\begin{array}{l}106 \cdot 42 \\
159 \cdot 1 \\
268 \cdot 23\end{array}$ & $\begin{array}{l}107 \cdot 94 \\
190 \cdot 25 \\
394 \cdot 49\end{array}$ & $\begin{array}{l}70 \cdot 11 \\
58 \cdot 59 \\
61 \cdot 42\end{array}$ & $\begin{array}{l}51 \cdot 53 \\
108 \\
226.8\end{array}$ & $\begin{array}{l}2 \\
3 \\
4\end{array}$ & $\begin{array}{r}942 \\
1018 \\
2918\end{array}$ & $\begin{array}{l}12 \\
13 \\
10\end{array}$ \\
\hline
\end{tabular}


Table 4 Calculated mean radiation exposure ( $m G y)$

\begin{tabular}{lrll}
\hline & Angiography & Fluoroscopy & Total \\
\hline Venous only group & $66 \cdot 6$ & $148 \cdot 2$ & $214 \cdot 8$ \\
Venous and arterial group & $266 \cdot 5$ & $164 \cdot 7$ & $431 \cdot 2$ \\
\hline
\end{tabular}

their hospital stay increased to four nights from the mean of 2 . One patient in the venous only group developed a supraventricular tachycardia after device deployment and required intravenous adenosine for cardioversion.

Deployment of the proximal arms in the aorta was recognised before release in three patients from the venous only group. In these cases the entire device was successfully withdrawn, remounted, and correctly deployed. In one case the size of the patient necessitated stripping of the green plastic off the delivery catheter so that the introducer sheath could be down sized to a 7 French gauge sheath for a $12 \mathrm{~mm}$ device. Deployment was successful. One patient from the failed venous only group, with a small residual shunt and a 17 $\mathrm{mm}$ device, had a tie placed around the device at the time of surgical closure of an atrial septal defect.

\section{Discussion}

A venous only approach using a single angiogram is as effective in achieving arterial duct occlusion using the Rashkind double umbrella device as the traditional arterial and venous method using multiple angiograms. The incidence of complications was not significantly different between the two groups in this series. In six patients the venous only approach failed in either gaining access to the patent arterial duct or defining it before or after device deployment. There was no significant difference in the rates of total occlusion in the two groups; however, the number of catheters used, the duration of the procedure, the volume of angiographic contrast used, and the radiation exposure were all significantly less in the venous only group than in the venous and arterial group.

Previous reports on the Rashkind double umbrella device have concentrated on follow up studies and residual shunting. ${ }^{5-7}$ This is the first report looking at different techniques for implantation.

Failure of the venous only technique was caused by the anatomy of the arterial duct in six of the seven patients. It is unlikely that two dimensional echocardiography with colour flow mapping will be able to identify ducts in which an arterial approach is required. Even if it could, the minimum time, effort, and radiation dose required to try and cross the duct from the venous side and perform a single angiogram warrant an attempt before arterial cannulation.

The increased screening time in the failed venous only group was related to setting up arteriovenous guidewire loops, balloon angioplasty of the arterial duct, and difficulties in positioning the long sheath. Despite this increase overall procedure times for this group were not significantly longer than the venous and arterial group and the dye volume per kilogram was not greater. Therefore there is no significant additional penalty for starting with the venous only method and, because of some necessity, changing to a venous and arterial method.

The absence of arterial pressure monitoring during the venous only procedures may be of concern to those who advocate arterial pressure monitoring during all interventional procedures. However, we would argue that these patients are otherwise healthy individuals and are a relatively low risk group as shown by the low reported rate of serious complications. ${ }^{5-7}$ We consider that cuff blood pressure monitoring by an anaesthetist is adequate for many of these patients but recognise the need for arterial pressure monitoring when there are other significant cardiovascular abnormalities which might be compounded by catheter occlusion of the arterial duct, for example cardiomyopathy.

One of the major factors in this series was the learning curve. Once training with the combined arterial and venous technique had been completed it was not until further experience had been satisfactorily gained with another 40 cases that the operators considered that a change in technique could be applied. There was a significant reduction in procedure time, although the change did not lead to a reduction in fluoroscopy time. Other factors that may be of importance but are not visible in the analysis are the training of junior staff during the venous only phase of the study.

As well as being as effective as a venous and arterial approach we consider that there are several important advantages from using a venous only approach. Avoidance of the complications of an arterial puncture is of considerable benefit. ${ }^{89}$ Femoral artery thrombosis is a relatively common complication and signs of arterial insufficiency are generally absent because collateral pathways usually open quickly in children. The problem may be undetected until the child develops signs of arterial insufficiency such as reduced limb growth or claudication. ${ }^{10}$ Avoiding arterial puncture also assists in keeping inpatient stay to a minimum. Arterial access will be required in some patients.

The radiation dose is greatly reduced in the venous only group of patients because of the reduction in the number of angiograms (table 2). Fewer angiograms could be used with a venous and arterial method. Since the working party report on the exposure of cardiologists to radiation ${ }^{11}$ there has been heightened awareness of the risks to health of the patient and the operator in the catheter laboratory. It is accepted that all exposures should be as low as reasonably achievable (ALARA principle). Cineangiography delivers one of the highest radiation dosages to patients and consequently to staff. ${ }^{11}$ The radiation dosage is often as much as 10 times greater than that for more common radiological procedures. ${ }^{12}$ Measurements of radiation exposure in children undergoing pulmonary valvuloplasty 
showed extremely high skin doses to the right lateral chest and estimated these to be equivalent to 1000 chest radiographs in a single session. ${ }^{13}$ The radiation exposure in the venous and arterial group was correspondingly high compared with the radiation dose of a single chest radiograph of $0.05 \mathrm{mGy}$ in a neonate. Chest imaging results in a radiation dose to sensitive organs such as the thyroid, breast, and red bone marrow. ${ }^{14}$ In addition, the beam angulation used in axial cineangiography results in an increased overall dose because of oblique projections as well as an increased dose to the gonads (G Testoni et al, proceedings of the international congress of the International Radiation Protection Association, Sydney, 1988).

Estimates of radiation risk may be assessed with respect to radiation induced cancers and other harmful effects. The fatal leukaemia risk factor in children aged $0-10$ years is $0.5 \times$ $10^{-2} / \mathrm{Sv} .{ }^{15}$ This represents the risk of excess cancers per Sievert. These measurements are for chest irradiation and the effective dose equivalent is $0.06 \times$ the estimated skin entry dose (conference report on dosimetry in diagnostic radiology, series $40 \mathrm{HPA}$, London, 1984). Using these figures from the literature and our calculations, the calculated risk factor for the venous only group is $1.1 \times 10^{-4}$ and for the venous and arterial group $1.5 \times 10^{-4}$. It can therefore be predicted that in the venous only group one patient of 9100 , and in the venous and arterial group one patient in 6600 will develop a malignancy as a result of radiation exposure. It must be emphasised that our calculations and the quoted risk factors are estimates; however, we consider that the order of magnitude for the calculations is correct.

Any reduction in the number of angiograms therefore has a very considerable reduction in radiation risk. The change in our practice has led to a $60 \%$ reduction in the number of angiograms taken during the procedure. As cineangiography accounts for a large proportion of the total dose, the overall reduction in primary exposure of the patient and scattered exposure of the operators is highly statistically significant. It is of note that fluoroscopy times were not significantly reduced in the venous only group. Insertion of an arterial sheath is not performed under fluoroscopic control and the main steps in the deployment and release of the device are unchanged in the two groups.

The newer non-ionic contrast agents are theoretically safer than the ionic contrast agents and do not cause the same cellular effects and increase in intravascular volume. ${ }^{16}$ Toxic effects, however, may occur with the high volumes used in cardiac catheterisation particularly in children with impaired renal function and premature infants. Any reduction in contrast dose is beneficial in these vulnerable groups.

The bulk of the cost of the procedure is taken up by the price of the device. However, new devices at lower costs are becoming available. The potential savings in terms of num- bers of catheters, sheaths, wires, and angiography dye are not insubstantial when considering the high cost of paediatric interventional catheterisation.

\section{Conclusions}

A single venous catheter approach using one angiogram is as effective as the traditional method of patent arterial duct occlusion using the Rashkind double umbrella device. The venous only approach results in a lower radiation dose to patient and operator and a reduction in the volume of contrast agent used. Further reductions in radiation dose may be achieved by using single plane angiography. The complications of an arterial puncture are avoided in the venous only method. Shorter procedure times and fewer consumables lead to cost savings. Initially, operators may consider using venous and arterial approaches coupled with multiple angiograms, but with experience we would advocate a venous only approach. Arterial cannulation being reserved for specific indications such as an inability to cross the arterial duct from the venous side.

We are grateful to Dr Robert Arnold and Dr Ian Peart for allowing us to report their patients, Jean Beamer and Chris allowing us to report their patients, Jean Beamer and Chris Dr Audrey Smith for her comments on the manuscript. SEA is supported by a British Heart Foundation grant.

1 Report of the European Registry. Transcatheter occlusion of persistent arterial duct. Lancet 1992;340:1062-6.

2 Rashkind WJ, Mullins CE, Hellenbrand WE, Tait M. Non surgical closure of patent ductus arteriosus: clinical application of the Rashkind PDA occluder system. Circulation 1987;75:583-92.

3 Krichenko A, Benson LN, Burrows P, Moes CA, McLaughlin P, Freedom RM. Angiographic classification of the isolated, persistently patent ductus arteriosus and implications for percutaneous catheter occlusion. Am f Cardiol 1989;63(12):877-80.

4 Cameron J. Radiation dosimetry. Environ Health Perspect 1991;91:45-8.

5 Dyck JD, Benson LN, Smallhorn JF, McLaughlin PR, Freedom RM, Rowe RD. Catheter occlusion of the per62(16): 1089-92.

6 Hosking MCK, Benson LN, Musewe NN, Dyck JD, Freedom RM. Transcatheter occlusion of the persistently patent ductus arteriosus. Circulation 1991;84: tently pate $2313-7$.

7 Ali-Khan MA, al-Yousef S, Mullins CE, Sawyer W. Experience with 205 procedures of transcatheter closure of ductus arteriosus in 182 patients, with special reference to residual shunts and long-term follow-up. ence to residual shunts and long-term foll
T Thorac Cardiovasc Surg 1992;104(6):1721-7.

8 Humitz RA, Franken EA, Girou DA, Smith DA, Smith WL. Angiographic determination of arterial patency after percutaneous catheterisation in infants and small children. Circulation 1977;56:102-5.

9 Burrows PE, Benson LN, Williams WG, et al. Iliofemoral arterial complications of balloon angioplasty for systemic obstructions in infants and children. Circulation 1990;82: 1697-704

10 Jacobsson B, Cangren LE, Ledvall G, et al. A review of children after arterial catheterisation of the leg. Pediatr Radiol 1973;1:96-9.

11 Camm AJ, Reid J, Raphael M, et al. Radiation hazards to the cardiologist. A report of a subcommittee of the British Cardiac Society. Br Heart f 1993;70:489-96.

12 Chapple CL, Faulkner K, Hunter EW. Energy imparted to neonates during $\mathrm{X}$-ray examinations in a special care neonates during X-ray examinations
baby unit. Br $\mathcal{F}$ Radiol 1994;67:366-70.

13 Wu JR, Huang TY, Wu DK, Hsu PC, Weng PS. Radiation exposure of paediatric patients and physicians during cardiac catheterisation and balloon pulmonary valvuloplasty. Am $\mathcal{F}$ Cardiol 1991;68:221-5.

14 Marshall NW, Faulkner K, Busch HP, Marsh DM, Pfenning $H$. An investigation into the radiation dose associated with different imaging systems for chest radiology. Br f Radiol 1994;67:353-9.

15 Richardson RB. Past and revised risk estimates for cancer induced irradiation and their influence on dose limits. $B$

16 Wood BP, Smith WL. Pulmonary oedema in infants following injection of contrast media for urography. Radiology 1981;139:377-9. 